\title{
An epidemiological study of dog bite cases in a rural area of Salem, Tamil Nadu
}

\author{
Sangeetha S. ${ }^{1 *}$, Shakthi Shri Hari M.V. ${ }^{2}$, Devi M. ${ }^{3}$, Kumar R. ${ }^{4}$, Sathana R. ${ }^{5}$, Renasre M. ${ }^{6}$, \\ Shanadhani K. ${ }^{7}$
}

DOI: https://doi.org/10.17511/ijphr.2018.i2.08

\footnotetext{
1* Sangeetha S., Professor and HOD, Department of Community Medicine, Vinayaka Mission's Kirupananda Variyar Medical College Hospital, Salem, Tamil Nadu, India.

2 Shakthi Shri Hari M.V., Interns, Vinayaka Mission's Kirupananda Variyar Medical College Hospital, Salem, Tamil Nadu, India.

3 M. Sarala Devi, Interns, Vinayaka Mission's Kirupananda Variyar Medical College Hospital, Salem, Tamil Nadu, India.

${ }^{4}$ R. Saravana Kumar, Interns, Vinayaka Mission's Kirupananda Variyar Medical College Hospital, Salem, Tamil Nadu, India.

5 Sathana R., Interns, Vinayaka Mission's Kirupananda Variyar Medical College Hospital, Salem, Tamil Nadu, India.

6 Renasre M., Interns, Vinayaka Mission's Kirupananda Variyar Medical College Hospital, Salem, Tamil Nadu, India.

7 Shanadhani K., Interns, Vinayaka Mission's Kirupananda Variyar Medical College Hospital, Salem, Tamil Nadu, India.
}

Introduction: Rabies is a viral zoonosis. In up to $99 \%$ of cases, domestic dogs are responsible for rabies virus transmission to humans. About $30 \%$ of the victims of dog bites are children under the age of 15. Objective: To assess the epidemiological pattern of dog bite cases, which formed the majority of cases attending anti-rabies clinic. Materials and Methods: This study was conducted at the Primary Health Centre,Poolavari, Salem, Tamil Nadu, India between Feb 1 st- May $1^{\text {st }} 2018$. It is a cross sectional study, where all dog bite cases attending injection OPD were studied. Results: Highest percentage of dog bite victims belonged to the age group of $5-25$ Years (33.7\%). The bites were mostly by pet dogs (75.5\%). $91.8 \%$ of the dogs were not vaccinated. Running, patting were the most common factors leading to dog bites (50.0\%). 52\% of the study population had awareness of first aid for dog bite. $88.8 \%$ population had awareness about Anti rabies vaccines for dog bites. Conclusion: The study concludes that awareness of first aid for dog bites ,pet dog vaccination, awareness about Anti rabies vaccine for dog bites and completion of the treatment should be increased in the rural population.

Keywords: Dog bite, Rural Area, Vaccination, Epidemiology

Corresponding Author

Sangeetha S., Professor and HOD, Department of Community Medicine, Vinayaka Mission's Kirupananda Variyar Medical College Hospital, Salem, Tamil Nadu, India.

Email: balamurugan.sangeetha@rediffmail.com
How to Cite this Article

Sangeetha S, Shakthi SHMV, Sarala MD, Kumar RS, Sathana R, Renasre M, Shanadhani K. An epidemiological study of dog bite cases in a rural area of Salem, Tamil Nadu. Public Health Rev Int J Public Health Res. 2018;5(2):99-104. Available From https://publichealth.medresearch.in/index.php/ijphr/ article/view/89 article/view/89
To Browse

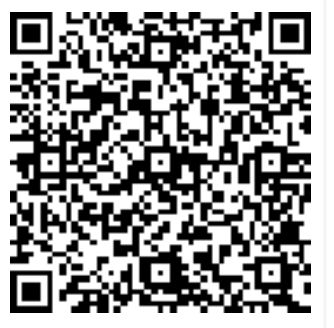

,




\section{Introduction}

Rabies, caused by bites of warm-blooded animals, is almost always fatal after the onset of clinical signs. The disease can efficiently be averted by avoiding contact with wild animals and postexposure prophylaxis (PEP) [1].

Canine rabies causes approximately 59,000 human deaths globally, over 3.7. million disability-adjusted life years, and 8.6 billion USD economic losses annually [2]. Around 15 million animal bites requiring post exposure rabies prophylaxis, the majority by dogs, occur in India every year [3].

There are little data on the incidence of animal bites from India. A study carried out a decade earlier had reported that the national incidence of animal bites as $17.4 / 1000$ population [4].

The World Health Organi-zation (WHO) supports targets for elimination of human rabies transmitted by dogs in South-East Asia by 2020. In this region, a 5-year plan (2012-2016) aims to halve the currently estimated number of human rabies deaths in endemic countries [5].

Data regarding community- based estimates of dog bites are required to track progress of such measures but are lacking in India, as they are the most common animal bites. The available studies on dog bites and rabies in India are mostly hospitalbased, and limited to disease management $[6,7,8]$.

\section{Objectives}

To study the epidemiologicalfactors of dog bite cases, which formed the majority of cases attending anti-rabies clinic of Primary Health Centre,Poolavari.

\section{Materials and methods}

Study area and Period: This study was conducted at the Primary Health Centre, Poolavari, Salem, India between Feb 1 st - May 1st 2018.

Study Type- It is a cross -sectional study, where all dog bite cases attending injection OPD were studied.

Sampling Design: Convenient sampling was done.

Study Method: Using pre-tested structured question-naire, the dog bite patients were interviewed, as they formed the most common animal bite cases.
They were asked about the dog that had bitten them, the type of dog-pet or stray, site of bite, reasons for bite, whether dog was vaccinated or not, time taken to seek treatment, first aid given and regarding post exposure prophylaxis. The socio demographic characteristics, epidemiological and associated factors for dog bites were also studied.

Inclusion Criteria: Only dog bite cases coming for vaccination were taken for study.

Exclusion Criteria: Other animal bite cases andthose who were unwilling to participate were excluded.

Statistical Analysis: Frequencies and Percentages

Percentages of the study population, their socio demographic characters, their nature of dog bites, first aid taken, vaccine administered and reasons for not vaccinating were studied.

\section{Results}

Table-1: Socio demographic characteristics of study population.

\begin{tabular}{|c|c|}
\hline $\begin{array}{l}\text { Socio-demographic } \\
\text { characters }\end{array}$ & $\begin{array}{l}\text { Subjects with Dog bites in the last } 3 \text { months } \\
\qquad \text { Number }(\%) \mathrm{n}=\mathbf{9 8}\end{array}$ \\
\hline \multicolumn{2}{|l|}{ Age (Years) } \\
\hline$<5$ & $1(1)$ \\
\hline $5-25$ & $33(33.7)$ \\
\hline $26-45$ & $32(32.7)$ \\
\hline $46-65$ & $30(30.6)$ \\
\hline$>65$ & $2(2)$ \\
\hline \multicolumn{2}{|l|}{ Sex } \\
\hline Male & $56(57.1)$ \\
\hline Female & $42(42.9)$ \\
\hline \multicolumn{2}{|l|}{ Education } \\
\hline Illiterate & $45(45.9)$ \\
\hline Primary & $36(36.7)$ \\
\hline Middle & $8(8.2)$ \\
\hline High school & $9(9.2)$ \\
\hline \multicolumn{2}{|l|}{ Occupation } \\
\hline House wife & $22(22.4)$ \\
\hline Weaver & $15(15.3)$ \\
\hline Student & $25(25.5)$ \\
\hline Coolie & $11(11.2)$ \\
\hline Agriculture & $12(12.2)$ \\
\hline Others & $13(13.3)$ \\
\hline \multicolumn{2}{|l|}{ Socio-economic class } \\
\hline Middle upper & $17(17.3)$ \\
\hline Middle lower & $11(11.2)$ \\
\hline Lower upper & $41(41.8)$ \\
\hline Lower lower & $29(29.6)$ \\
\hline
\end{tabular}


Socio-demographic characteristics of the study population were compared with one another to find which of the characteristic ranked the highest in association with dog bite. Most of the victims belonged to the age group 5-25 years (33.7\%). followed by age group 26-45 (32.7\%) and 45-65 years $(30.6 \%)$.

The percentage of male victims (57.1\%) were higher compared to the female victims (42.9\%). Dog bites in students ranked the highest of $25.5 \%$. Secondly, Coolie (11.2\%) and agricultural workers $(12.2 \%)$ recorded a total of $23.7 \%$ of dog bites, which results in a conclusion that occupational environment is one of the main risk factors for dog bites.

Most of the victims belonged to socio-economic class - lower upper (41.8\%), followedby Lower lower $(29.6 \%)$. Victims of classes Middle upper andMiddle lower recorded comparatively lower percentages of dog bites $(17.3 \%$ and $11.2 \%$ respectively).

Table-2: Showing dog bite cases bitten by type of dogs.

\begin{tabular}{|l|l|l|}
\hline \multicolumn{1}{|c|}{ Type of dog bites } & \multicolumn{1}{c|}{ Frequency } & \multicolumn{1}{c|}{ Percent } \\
\hline stray & 24 & 24.5 \\
\hline pet & 74 & 75.5 \\
\hline Total & 98 & 100.0 \\
\hline
\end{tabular}

$75.5 \%$ of the bites were by pet dogs. Stray dog bite was only $24.5 \%$. Thebite percentage was more by pet dogs.

Table-3: showing vaccination status of bitten dogs

\begin{tabular}{|l|l|l|}
\hline & \multicolumn{1}{|c|}{ Frequency } & \multicolumn{1}{c|}{ Percent } \\
\hline yes & 8 & 8.2 \\
\hline no & 90 & 91.8 \\
\hline Total & 98 & 100.0 \\
\hline
\end{tabular}

$91.8 \%$ of the pet dogs were not vaccinated. Only $8.2 \%$ of the dogs were vaccinated. The results of vaccination status of the bitten dog were unsatisfactory It was found that running and patting of the dogs were the most common factors leading to dog bites (50\%). Provoking gestures (27.6\%) and playing $(22.4 \%)$ were said to be other reasons by the bite victim.

Fig 1 shows that the most common bite site was leg $(56.1 \%)$, followed by hand $(27.6 \%)$. Bites in the trunk was $7.1 \%$ and the body bites was $3.1 \%$. Bites in the trunk and body were less common.

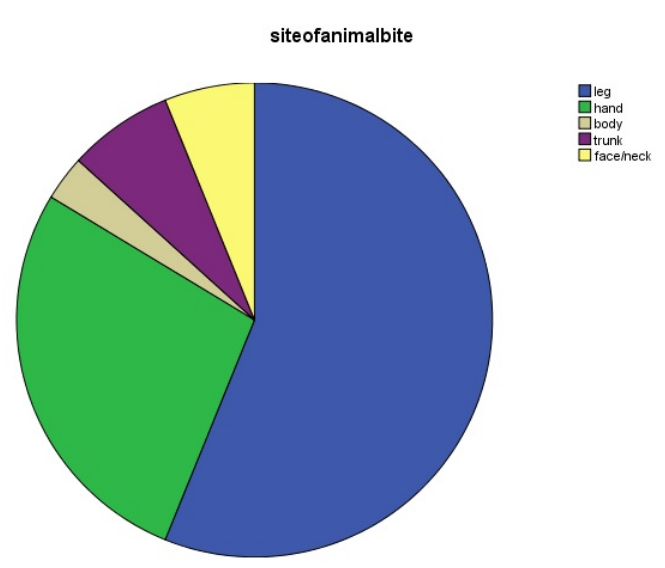

Fig-1: Distribution of site of dog bites

It was found that only $48 \%$ of the study population had awareness of first aid givenfor dog bite cases. Hence there is a need to create awareness regarding first aid to dog bite victims. Whereas, $88.8 \%$ of the study population was aware of Anti rabies vaccination for dog bites.

Table-4: shows distribution of duration before taking treatment for dog bites.

\begin{tabular}{|l|l|l|l|}
\hline $\begin{array}{c}\text { Duration before taking } \\
\text { treatment }\end{array}$ & \multicolumn{1}{|c|}{$\begin{array}{c}\text { Number of dog bite } \\
\text { cases }\end{array}$} & $\%$ \\
\hline \multirow{4}{*}{} & within $1 / 2 \mathrm{hr}$ & 30 & 30.6 \\
\cline { 2 - 4 } & $1 / 2-6 \mathrm{hrs}$ & 26 & 26.5 \\
\cline { 2 - 4 } & $6-12 \mathrm{hrs}$ & 28 & 28.6 \\
\cline { 2 - 4 } & $\begin{array}{l}\text { more than } \\
12 \mathrm{hrs}\end{array}$ & 14 & 14.3 \\
\cline { 2 - 4 } & Total & 98 & 100.0 \\
\hline
\end{tabular}

Table 4 shows that $30.6 \%$ of the victims took treatment within $1 / 2$ an hour of bite, $28.6 \%$ took treatment between 6-12 hours and $26.5 \%$ took treatment between $1 / 2$ - 6 hours. The percentage of victims who took treatment after $12 \mathrm{hrs}$ was $14.3 \%$.

Table-5: shows distribution of dog bites cases taken treatment.

\begin{tabular}{|l|l|c|}
\hline \multicolumn{1}{|c|}{ Type of treatment } & Frequency & $\%$ \\
\hline Allopathy & 80 & 81.6 \\
\hline $\begin{array}{l}\text { indigenous treatment (turmeric, kerosene, mud, } \\
\text { limestone, }\end{array}$ & 18 & 18.3 \\
\hline Total & 98 & 100.0 \\
\hline
\end{tabular}

$81.1 \%$ of the study population tookallopathy treatment and $18.3 \%$ underwent other forms of indigenous treatment like usage of turmeric, mud and limestone.94.9\% cases had taken Anti rabies vaccination, while $5.1 \%$ had not taken Anti rabies vaccination. 
Table-6: shows distribution of cases with complete treatment.

\begin{tabular}{|l|l|l|}
\hline \multicolumn{1}{|c|}{ Treatment taken } & \multicolumn{1}{c|}{ Frequency } & \multicolumn{1}{c|}{ Percent } \\
\hline complete & 74 & 75.5 \\
\hline incomplete & 24 & 24.5 \\
\hline Total & 98 & 100.0 \\
\hline
\end{tabular}

It was found that cases who completed treatment was only $75.5 \%$. $24.5 \%$ of the study population did not complete the treatment.

Table-7: shows reasons for incomplete treatment.

\begin{tabular}{|l|l|l|l|}
\hline \multicolumn{2}{|c|}{ Valid } & Frequency & Percent \\
\cline { 2 - 4 } & Others-fear of injection & 2 & 8.3 \\
\cline { 2 - 4 } & Ignorance & 2 & 8.3 \\
\cline { 2 - 4 } & Total & 20 & 83.3 \\
\hline
\end{tabular}

Ignorance was the main reason for incomplete treatment $83.3 \%$. Far distance and fear of injection were the other reasons for incomplete treatment.

\section{Discussion}

Our study conducted at Poolavari Primary Health Centreshowed that the $75.5 \%$ dog bite cases were caused by pet dogs. An epidemiological study of animal bites among rural population in Tamil Nadu, India showed similar results where bite by pet dogs were more common (59.42\%) [9].

The increased incidence of pet dog bites stresses the importance of pet dog care and vaccination. WHO sponsored National Multi-Centric Rabies survey showed that bite by stray dogs in rural area was $63.6 \%$ compared to the bite by pet dogs $36.4 \%$ in rural [10].

It was found in our Poolavari PHC study that most of the dog bite victims belonged to the age group of 5$25(33.7 \%)$, followed by victims in age group 26-45 $(32.7 \%)$ and victims in age group of $45-65$ $(30.6 \%)$. Victims belonging to age group $>65$ and $<5$ recorded less number of animal bites, $2 \%$ and $1 \%$ respectively.

Research paper on Knowledge, Attitude and Practices Regarding Dog Bites and its Management Among Adults in Rural Tamil Nadu showed results where people of age group 41-60 years recorded $29.8 \%$ of bites. But the highest was among the age group $20-40$ years (57.5\%) [11]. $57.1 \%$ victims of dog bites in our study population were males. $42.9 \%$ victims were females.
The results of WHO sponsored National Multi-Centric Rabies survey showed similar results in which victims were mostly males (68.5\%), female victims were lesser in percentage $(31.3 \%)$ in rural area [10].

Our study found that $45.9 \%$ dog bite victims were illiterate and victims who had finished their primary education were the second highest $(36.7 \%)$. It was observed by the epidemiological study of animal bites in Tamil Naduthat illiterate and people who had completed primary education both having an incidence of $21.74 \%$ each [9].

Our study shows that percentage of dog bites in students were $25.5 \%$ which is the highest. Bite percentage was second highest among the housewives which was $22.4 \%$, weavers had $15.3 \%$ of bites. An epidemiological study of animal bites among rural population in Tamil Nadu found that students had $34.78 \%$ of dog bites, the percentage of student victims were almost similar to our study [9].

A cross sectional study to understanding demographics of dog bite victims attending anti rabies ward in Chennai city, Tamil Nadu observed that bite percentage among studentswas $33.98 \%$ and among housewives was $10.16 \%$ [12]. Epidemiological study of animal bite victims in Central India found that student bite percentage was $18.2 \%$ and bite percentage in unemployed and house wife was $10.3 \%$ [13].

Our study showed that the most common factor leading to dog bites was running and patting about $50.0 \%$, bite due to provoking gestures was $27.6 \%$. Epidemiological study of animal bite victims in Central India found that $75.9 \%$ of bites were unprovoked and $24.1 \%$ of bites was due to provoking gestures [13] A cross sectional study to understanding demographics of dog bite victims attending anti rabies ward in Chennai city, Tamil Nadushowed that provoked bites was the highest $(60.55 \%)$ [12].

Ourstudy showed that the most common site of bite was leg $56.1 \%$. A cross sectional study to understanding demographics of dog bite victims attending anti rabies ward in Chennai city, Tamil Nadurecorded $59.77 \%$ bites in lower limb and $33.59 \%$ bites in upper limb[12].The vaccination status of bitten dog in our study shows that only $8.2 \%$ of dogs were vaccinated, the rest $91.8 \%$ of dogs were not vaccinated. 
A cross sectional study to understanding demographics of dog bite victims attending anti rabies ward in Chennai city, Tamil Nadufound that $33.59 \%$ of the dogs were vaccinated, $13.67 \%$ were not vaccinated, and the vaccination status of the other dogs were not known [12].

Ourstudy showed that $30.6 \%$ of victims took treatment within $1 / 2 \mathrm{hr}, 28.6 \%$ took treatment within $6-12 \mathrm{hrs}, 26.5 \%$ within $1 / 2-6$ hrs and only $14.3 \%$ took treatment after 12 hrs. An epidemiological study of animal bites among rural population in Tamil Nadu, India observed that $60.78 \%$ victims had taken treatment within $1 / 2 \mathrm{hr}, 9.8 \%$ had taken treatment within $6-12 \mathrm{hrs}$, and $13.73 \%$ victims had taken treatment after $12 \mathrm{hrs}$. The percentage of victims taking treatment after $12 \mathrm{hrs}$ were almost similar to our study [9].

Our Poolavari PHC study showed that $81.6 \%$ of the victims opted for allopathy treatment and only $18.3 \%$ took indigenous treatment with turmeric, kerosene, mud and limestone. A cross sectional study to understanding demographics of dog bite victims attending anti rabies ward in Chennai city, Tamil Nadu found that $50.78 \%$ washed wound with water/ soap with water as a first aid measure, $21.86 \%$ consulted Physician as first aid measure and $11.72 \%$ underwent unconventional intervention [12].

Prevalence of Dog Bites in Rural and Urban Slums of Delhi: A Community-based Study found that in rural area of Delhi $42.7 \%$ washed the wound with soap and water as first step ofmanagement, $2.4 \%$ washed the wound with water only, $25.9 \%$ sought help of qualified professional and $28.9 \%$ underwent traditional methods of treatment [14].

Ourstudyfound that $75.5 \%$ cases had completed the treatment, while $24.5 \%$ cases had not completed the treatment. The important reason for incomplete treatment $83.3 \%$, were ignorance about consequences of dog bites.Prevalence of Dog Bites in Rural and Urban Slums of Delhi: A Communitybased Study found that $82.5 \%$ of the bite victims coming from the rural area were not aware of the injections given after dog bite.

\section{Conclusion}

The dataconcludes thatLower socio-economic classes, and illiterates were prone to higher percentage of dog bites. Males had higher incidence compared to females, the reason being occupational environment.
Student victims were more compared to other occupations, the reason varied from one another (the main reason being running, patting and playing with dogs.). The bite from pet dogs were more common, whereas the awareness regarding pet dog vaccination was poor, which indirectly stresses the importance of pet dog vaccination by every dog owner to prevent Rabies.

The interns, who collected the data from dog bite victims gave them health education regarding awareness of first aid for dog bites,pet dog vaccination, awareness about Anti rabies vaccine for dog bites and completion of the treatment.

Suggestions: Pet dog vaccination should be intensified among general public along with awareness of first aid fordogbites, awareness about Anti rabies vaccine for dog bites and completion of the treatment to prevent deadly disease Rabies.

\section{Limitation}

This study was conducted only in the patients attending the Outpatient ward in the Poolavari PHC.

\section{Acknowledgement}

The authors are grateful to the Dean, and the Medical Superintendent of VMKV Medical College, Salem, for their permission to conduct the study and their encouragement. The authors wish to thank all the interns, Medical officer, field staff of Poolavari PHC and patients, who were participants for this study.

\section{Reference}

01. WHO. World Survey of Rabies. No-32;1996.

[Crossref]

02. Hampson K, Coudeville $L$, Lembo T, Sambo $M$, Kieffer A, Attlan $M$, et al. Estimating the global burden of endemic canine rabies. PLo $S$ Neglected Tropical Disease. 2015;9(5)0003786. [Crossref]

03. Sudarshan MK, Madhusudana SN, Mahendra BJ, Rao NS, Ashwath Narayana DH, Abdul Rahman $S$, et al. Assessing the burden of human rabies in India- Results of a National Multi-center Epidemiological survey. Int J Infect Dis. 2007; 11;29-35.

[Crossref] 
04. Sudarshan MK. Assessing burden of rabies in India- WHO sponsored National Multi-centric rabies survey, 2003. Indian Journal of Community Medicine. 2005;30(3)100-101. [Crossref]

05. WHO Fact Sheet. Geneva 2013- World Health Organization. .

[Crossref] [PubMed] [Google Scholar] [Crossref]

06. Gogtay NJ, Nagpal A, Mallad A, Patel K, Stimpson SJ, Belur $A$, et al. Demographics of animal bite victims \& management practices in a tertiary care institute in Mumbai, Maharashtra, India. Indian J Med Res. 2014;139(1)459-62.

[Crossref]

07. Ghosh A, Pal R. Profile of dog bite cases in an urban area of Kolkata, India. Nat J Community Med. 2014;5(3)321-4.

[Crossref]

08. Umrigar P, Parmar GB, Patel PB, Bansal RK. Epidemiology of animal bite cases attending municipal tertiary care centres in Surat city- A cross-sectional study. Nat J Community Med. 2013;4(1)153-7.

[Crossref]

09. S Sangeetha, Sujatha K, Roseline Fatima William. An epidemiological study of animal bites among rural population in Tamil Nadu, India. Int J Community Med Public Health. Jun 2016;3(6);1413-1418.

[Article] [Crossref]
10. M K Sudarshan, B J Mahendra, S N Madhusudana, D H Ashwath Narayana, Abdul Rahman, N S N Rao, F X- Meslin, Derek Lobo, K Ravikumar and Ganga-boraiah. An Epidemiological Study of Animal Bites in IndiaResults of A WHO Sponsored National MultiCentric Rabies Survey. J Commun Dis. 2006;38;32-39.

[Crossref]

11. Y Suba Joice, Zile Singh, Shib Sekhar Datta. Knowledge, Attitude and Practices Regarding Dog Bite and its Management Among Adults in Rural Tamil Nadu. Int J Sci Res. May 2016;5(5)586-589.

[Crossref]

12. Sukumar Bharathy, Lakshmana sami Gunaseelan. A Cross Sectional Study to Understanding Demographics of Dog Bite Victims Attending Anti Rabies Ward in Chennai City, Tamil Nadu, India. Advances in Animal and veterinary Sciences. February 2017;5(2)78-82. [Crossref]

13. Neera Marathe, Sanjeev Kumar. Epidemiological study of animal bite victims in Central India- a cross sectional institutional study. Int J Community Med Public Health. 2016 Jan; 3(1)78-82.

DOI: [Article] [Crossref]

14. S Sharma, A Agarwal, AM Khan and GK Ingle. Prevalence of Dog Bites in Rural and Urban Slums of Delhi- A Community-based Study. Ann Med Health Sci Res. 2016 Mar-Apr; 6(2) 115119.

doi: $10.4103 / 2141-9248.181836$ [Crossref] 